\title{
EVALUASI KUALITAS ESTETIKA FASADE BANGUNAN DENGAN PENDEKATAN BIRKHOFF AESTHETIC MEASURE
}

\author{
Donna Mulyo Saputro'), Baritoadi Buldan Rayaganda Rito ${ }^{2)}$ \\ Program Profesi Arsitek Universitas Islam Indonesia ${ }^{1,2)}$ \\ Jalan Kaliurang No.Km. 14,5, Besi, Umbulmartani, Kec. Ngemplak, Kabupaten Sleman, \\ Daerah Istimewa Yogyakarta, Indonesia \\ Email: donnamulyo8@ gmail.com ${ }^{1)}$
}

\begin{abstract}
ABSTRAK
Perencanaan sebuah bangunan properti harus memiliki keunikan dan daya tarik agar dapat diterima oleh konsumen. Daya tarik dari sebuah desain bangunan dapat meningkatkan daya beli konsumen terhadap unit properti. Salah satu upaya dalam meningkatkan daya tarik bangunan adalah dengan meningkatkan nilai estetika sebuah wajah bangunan (fasade bangunan). Dari data penelitian yang sudah pernah dilakukan, pengaruh desain fasade bangunan terhadap minat beli konsumen berada di peringkat kedua setelah lokasi unit. Untuk mengetahui tingkat kualitas estetika suatu fasade bangunan dapat dihitung dengan menggunakan metode Birkhoff Measure. Metode tersebut dilakukan dengan memberikan aspek penilaian terhadap responden, kemudian responden akan memberikan penilaian secara kuantitatif dari aspek yang dinilai. Nilai dari aspek tersebut akan dihitung menggunakan rumus yang sudah ada hasilnya akan menjadi nilai kualitas sebuah fasade bangunan. Dari hasil tersebut akan diketahui desain fasade yang memiliki nilai estetika tinggi yang dapat diterima oleh konsumen secara umum. Perhitungan dengan metode Birkhoff Measure perlu dilakukan agar meminimalisir kegagalan dalam desain fasade bangunan, sehingga desain bangunan yang ditawarkan dapat menambah minat daya beli konsumen terhadap unit property tersebut.
\end{abstract}

Kata kunci: Estetika, Fasade bangunan, Unit properti

\begin{abstract}
Planning a property building must be unique and attractive in order to be accepted by consumers. The attractiveness of a building design can increase the purchasing power of consumers towards property units. One of the efforts in increasing the attractiveness of buildings is by increasing the aesthetic value of a building's face (building facade). From the research data that has been done, the influence of building facade design on consumer buying interest is ranked second after the location of the unit. To determine the level of aesthetic quality of a building facade, it can be calculated using the Birkhoff Measure method. The method is carried out by providing aspects of the assessment of respondents, then respondents will provide a quantitative assessment of the aspects assessed. The value of this aspect will be calculated using an existing formula, the result will be the quality value of a building facade. From these results it will be known that the facade design has a high aesthetic value that can be accepted by consumers in general. Calculations using the Birkhoff Measure method need to be done in order to minimize failures in the design of the building facade, so that the design of the building offered can add to the consumer's purchasing power to the unit property.
\end{abstract}

Keyword: Aesthetic, Building Façade, Property Unit 


\section{PENDAHULUAN}

Perkembangan dunia arsitektur di Indonesia mengalami perkembangan yang pesat dalam decade belakangan ini. Hal ini dapat dilihat dari beberapa tokoh arsitek nusantara yang mulai menduni. Selain itu dampak dari adanya perkembangan arsitektur yang pesat di indonesia terlihat dari banyaknya masyarakat menggunakan jasa Arsitek dalam membuat perancangan baik itu hunian maupun bangunan yang bersifat komersial. Masyarakat mulai memahami dengan peran arsitek dalam perancangan sebuah bangunan. Mereka menggunakan jasa arsitek dalam perancangan bangunan dengan bertujuan untuk mendapatkan sebuah rancangan bangunan yang baik, efisien dan indah ketika di pandang. Berdasarkan dari penelitian yang dilakukan oleh Yordie Wicaksono dan Ary Deddy Putranto tentang minat pembeli unit properti terhadap design fasade bangunan yang dilakukan pada tahun 2017 di Jakarta Selatan, dapat di tarik sebuah kesimpulan bahwa salah satu faktor yang memperngaruhi minat pembelian properti adalah desain fasade. Untuk mengetahui tingkat baik dan bagusnya fasade bangunan perlu adanya nilai yang menunjukan kualitas fasade bangunan tersebut.

\section{TINJAUAN PUSTAKA}

Rumus Birkhoff dapat digunakan dalam Arsitektur dengan mendefinisikan kembali parameter persamaan; Order dan Complexity, dimana ia bertindak sebagai indeks keindahan alam/kehidupan arsitektur yang dimiliki gedung. Patut dicatat bahwa ukuran ini menetralkan pengaruh latar belakang sejarah bangunan, fungsi, dan faktor-faktor yang mempengaruhi lainnya di bawah gagasan mencari hanya aspek formal bangunan. Rumusan perhitungan ini bertujuan untuk menguji penerapan dan kredibilitas ukuran estetika Birkhoff sebagai alat analitik dan kritik untuk penilaian estetika arsitektur. Birkhoff dan pengikutnya mempresentasikan interpretasi matematis dari estetika formal objek melalui hubungan terbalik antara Order dan Kompleksitas bentuk objek sebagai:

$$
\begin{aligned}
& \text { The Aesthetic Masure }=\text { Order / Complexity } \\
& \qquad \begin{array}{l}
\mathbf{M}=\mathbf{O} / \mathbf{C} \\
\mathrm{M} 1=\mathrm{O} * \mathrm{C} 1, \mathrm{M} 2=\mathrm{O}+\mathrm{C}
\end{array}
\end{aligned}
$$

Aesthetic Measure (M) dalam istilah arsitektur adalah indeks estetika keindahan alam/ kehidupan arsitektur. Order adalah pembuktian bahwa objek memiliki hubungan geometris dalam komposisinya (Arnheim, 1977). Karakteristik tatanan sangat memungkinkan untuk menghasilkan perasaan positif, sementara ambiguitas, pengulangan yang tidak semestinya, dan ketidaksempurnaan menghasilkan perasaan negatif. Secara arsitektur, Order (O) dihitung berdasarkan 6 aspek yaitu: Symmetry (S), Repetition (R), Equilibrium (E), Disposition (D), and Color harmonyl (H), Randomness (nf) dianggap sebagai faktor negatif yang mempengaruhi Order. Dan Complexity diukur berdasarkan 4 aspek yaitu Form complexity (F.C), Ornament (Orn), Silhouette differentiation (S.d), and Color Contrast (C.c).

\section{METODOLOGI PENELITIAN}

Penelitian ini menggunakan metode kuisioner dengan pendekatan penilaian kuantitatif diskriptif. Kuesioner merupakan instrumen didalam teknik komunikasi tidak langsung. 
Kuesioner sebagai alat pengumpul data adalah sejumlah pertanyaan tertulis, yang harus dijawab oleh responden. Langkah permulaan dilakukan dengan penelusuran berbagai studi literatur terkait dengan hal yang akan diteliti, yaitu mengenai pengukuran nilai estetika fasade bangunan. Dalam kasus ini diambil studi beberapa fasade bangunan, kemudian dilakukan penilaian menggunakan parameter sesuai dengan pendeketan yang digunakan.

Tabel 1. Parameter Penelitian Kualitas Fasade Bangunan

\begin{tabular}{llccc}
\hline \multirow{2}{*}{ No } & \multirow{2}{*}{ Variable } & \multicolumn{2}{c}{ Scematic Scale } & \multirow{2}{*}{ Score } \\
\cline { 3 - 4 } & & \multicolumn{1}{c}{$(-)$} & $(+)$ & \\
\hline 1 & Symmetry (S) & Asymmetry & Symmetry & $0-2$ \\
2 & Repetition (R) & No repeated & Repeated & $0-2$ \\
3 & Equilibrium (E) & Contrast & Conformable & $0-2$ \\
4 & Disposition (D) & Side & Center & $0-2$ \\
5 & Color Harmony (H) & No color & Uniform colors & $0-2$ \\
6 & Negative Factor (N.f) & Dissatisfaction & Imperfection & $0-2$ \\
7 & Form Complexity(F.c) & No curve & Curves & $0-2$ \\
8 & Ornament (Orn) & Lack & Details & $0-2$ \\
9 & Solhouette Differentiation (S.d) & No turn & More turn & $0-2$ \\
10 & Color Cotrast (C.c) & Uniform color & Contrasting color & $0-2$ \\
\hline
\end{tabular}

Metode analisis dengan menerpakan rumus Birkhoff pada penilaian yang sudah dilakukan kepada responden dan menyocokanya dengan hasil penilaian kontrol. Untuk mencari nilai Measure berdasarkan Order/Complexity.

$$
\begin{gathered}
\operatorname{Order}(\mathrm{O})=\mathrm{S}+\mathrm{R}+\mathrm{E}+\mathrm{D}+\mathrm{H}-\mathrm{nf} \\
0 \leq \operatorname{Order}(\mathrm{O}) \leq 10 \\
\text { Complexity }(\mathrm{C})=\text { F.C. }+ \text { Orn. }+ \text { S.d. }+ \text { C.c } \\
0 \leq \text { Complexity }(\mathrm{C}) \leq 8
\end{gathered}
$$

Aesthetic Measure (M) meningkat dengan meningkatnya Order (O), dan akan menurun dengan meningkatnya Complexity (C). Untuk Order rendah dan Complexity lebih tinggi, skor Aesthetic Measure: 0,125 $\leq \mathrm{M} \leq 1$, ini mengekspresikan sebuah bangunan dengan estetika yang buruk dan dengan tingkat daya tarik yang tinggi. Ketika Order lebih tinggi dan Complexity tinggi, skor Aesthetic Measure: $1 \leq \mathrm{M} \leq 2$, ini mengekspresikan sebuah bangunan dengan estetika yang sangat baik dan dengan tingkat daya tarik yang tinggi. Ketika Order lebih tinggi dan Complexity Rendah, skor Aesthetic Measure: $2 \leq \mathrm{M} \leq 4$, ini mengekspresikan bangunan yang cukup estetis dengan tingkat daya tarik rata rata. Ketika Order jauh lebih tinggi daripada Complexity, skor Aesthetic Measure: $4 \leq \mathrm{M} \leq 10$, ini mengekspresikan struktur yang sangat teratur dengan jumlah detail atau kompleksitas paling sedikit. Ketika Order sama dengan Complxity, $\mathrm{M}=1$, ini adalah nilai yang tidak dapat dijadikan hasil akhir, jika $\mathrm{M}=1$ maka untuk mencari nilai $\mathrm{M}$ menggunkan persamaan kedua, yaitu $(\mathrm{M} 1=\mathrm{O} * \mathrm{C})$ 


\section{HASIL DAN PEMBAHASAN}

Dari penilain responden yang melakukan penilaian kualitas estetika berdasarkan beberapa variabel penilaian, berdasarkan data dari tabel di atas dapat dilihat rata rata nilai untuk aspek Symmetry (S) berada di angka 1,3; Equilibrium (E) berada di angka 1,35; Desposisi (D) di angka 1,15; Color Harmony (H) berada di angka 1,3; Form Complexity (F.C) berada di angka 1,05; Ornament (orn) di angka1,2 dan Silhouette Differentation (S.d) di angka 1,3. Dari 7 variabel penilaian tersebut, mereka memilik nilai rata rata lebih dari 1 (satu), dari parameter yang sudah di bahas pada bab sebelumnya penilaian variabel yang memilik hasil > 1 maka penilaian tersebut lebih cenderung positif.

Sedangkan untuk aspek Repetisi (R), penilaian berdasarkan dari 20 responden nilai untuk aspek tersebut memilik rata rata 1 (satu). Untuk hasil penilaian dengan nilai rata-rata di angka 1, penilaian tersebut lebih cenderung netral (tidak condong ke nagitif ataupun positif).

Dan untuk aspek Negative factor (N.f) dan Color Contrast (C.c) masing-masing memiliki nilai rata rata 0,95 dan 0,65 . Keduanya sama sama memiliki penilaian kuang dari 1 (satu) yang menurut parameter yang sudah dijelaskan pada bab sebelumnya, penilaian dangan hasil $<1$ lebih cenderung negatif.

Tabel 2. Hasil Penilaian Responden

\begin{tabular}{|c|c|c|c|c|c|c|c|c|c|c|c|c|c|}
\hline \multirow{2}{*}{ Responden } & \multicolumn{6}{|c|}{$\mathbf{O}$} & \multicolumn{4}{|c|}{ C } & \multirow{2}{*}{ O } & \multirow{2}{*}{$\mathbf{C}$} & \multirow{2}{*}{$\mathbf{M}$} \\
\hline & $\mathbf{S}$ & $\mathbf{R}$ & $\mathbf{E}$ & D & $\mathbf{H}$ & $\mathbf{N f}$ & Fc & Or & Sd & $\mathrm{Cc}$ & & & \\
\hline 1 & 1 & 0 & 2 & 2 & 2 & 0 & 1 & 1 & 2 & 0 & 7 & 4 & 1.7 \\
\hline 2 & 1 & 0 & 2 & 2 & 2 & 0 & 2 & 2 & 1 & 1 & 5 & 6 & 0.8 \\
\hline 3 & 0 & 0 & 2 & 1 & 1 & 0 & 1 & 1 & 1 & 0 & 4 & 3 & 1.3 \\
\hline 4 & 1 & 2 & 2 & 1 & 1 & 2 & 0 & 1 & 2 & 0 & 9 & 3 & 3 \\
\hline 5 & 2 & 1 & 2 & 1 & 1 & 2 & 2 & 2 & 2 & 1 & 9 & 7 & 1.2 \\
\hline 6 & 2 & 0 & 0 & 2 & 2 & 1 & 1 & 0 & 1 & 0 & 5 & 2 & 2.5 \\
\hline 7 & 2 & 1 & 1 & 1 & 1 & 0 & 2 & 1 & 2 & 1 & 7 & 6 & 1.6 \\
\hline 8 & 1 & 1 & 2 & 2 & 2 & 0 & 1 & 2 & 1 & 1 & 7 & 5 & 1.4 \\
\hline 9 & 1 & 2 & 0 & 0 & 0 & 2 & 0 & 0 & 1 & 1 & 6 & 2 & 3 \\
\hline 10 & 0 & 2 & 2 & 2 & 2 & 1 & 2 & 2 & 0 & 1 & 9 & 5 & 1.8 \\
\hline 11 & 2 & 1 & 1 & 1 & 1 & 0 & 1 & 2 & 1 & 0 & 5 & 4 & 1.2 \\
\hline 12 & 1 & 2 & 2 & 1 & 1 & 2 & 0 & 1 & 2 & 0 & 10 & 3 & 3.3 \\
\hline 13 & 2 & 1 & 1 & 0 & 0 & 1 & 1 & 0 & 2 & 1 & 5 & 4 & 1.2 \\
\hline 14 & 1 & 1 & 1 & 1 & 1 & 1 & 2 & 1 & 1 & 0 & 6 & 4 & 1.5 \\
\hline 15 & 1 & 1 & 2 & 2 & 2 & 1 & 1 & 0 & 0 & 2 & 9 & 3 & 3 \\
\hline 16 & 1 & 0 & 2 & 1 & 1 & 2 & 0 & 2 & 1 & 1 & 7 & 4 & 1.7 \\
\hline 17 & 2 & 1 & 0 & 1 & 1 & 1 & 1 & 2 & 2 & 2 & 6 & 7 & 0.8 \\
\hline 18 & 1 & 2 & 0 & 0 & 0 & 1 & 1 & 1 & 1 & 0 & 6 & 3 & 2 \\
\hline 19 & 2 & 1 & 2 & 1 & 1 & 1 & 0 & 1 & 1 & 1 & 8 & 3 & 2.6 \\
\hline \multirow[t]{2}{*}{20} & 2 & 1 & 0 & 2 & 2 & 1 & 2 & 2 & 2 & 0 & 8 & 6 & 1.3 \\
\hline & 1.3 & 1 & 1.3 & 1.1 & 1.2 & 0.9 & 1.0 & 1.2 & 1.3 & 0.6 & 6.9 & 4.2 & 1.8 \\
\hline
\end{tabular}

Dari 20 responden yang sudah melakukan penilaian, dapat disimpulkan nilai Measure (M) berada diantara 0,125 sampai dengan 4 . Dari 20 nilai yang sudah ada, terdapat 2 responen yang memberikan penilaian $0,125<\mathrm{M}<1 ; 11$ responden dengan penilaian $1<\mathrm{M}<2$ dan 7 responden dengan penilaian $2<\mathrm{M}<4$. Dari data diatas dapat disimpulakn rata rata nilai Measure (M) yaitu 1,850476. 




Gambar 1. Hasil Penilaian Kontrol

Diagram Akhir dari Analisa Kontrol.

Dari penilaian kontrol didapatkan nilai akhir dari kualitas estetika bangunan di angka 4,25 . Nilai tersebut cenderung bangunan memiliki nilai estetika yang bagus. Sedangkan nilai dari responden untuk penilaian terkait daya tarik, secara keseluruhan daya tarik bangunan memiliki nilai 4,3 . Nilai tersebut cenderung bangunan memiliki tingkat daya tarik yang menarik.

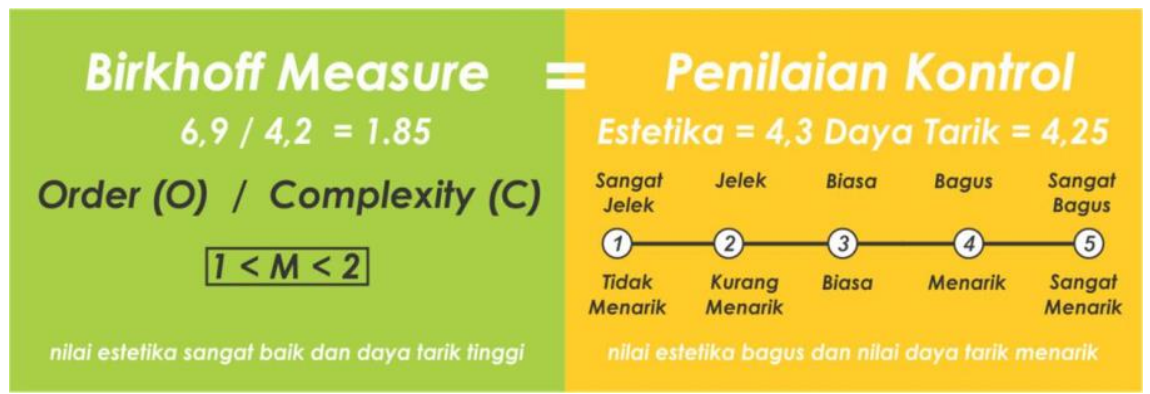

Gambar 2. Hasil Penelitian Akhir

Korelasi Antara Metode Perhitungan dengan Penilaian Kontrol

Penilaian Birkhoff didapatkan hasil akhir berupa nilai estetika bangunan sangat baik dengan daya tarik yang tinggi, dan untuk penilaian kontrol memiliki hasil akhir yaitu bangunan memiliki nilai estetika yang bagus dengan tingkat daya tarik yang menarik. Dari keduanya dapat ditarik kesimpulan bahwa penilaian dengan menggunakan Birkhoff Measure memiliki hasil yang sama dengan penilaian kontrol. Hal tersebut berarti Birkhoff Measure dapat mewakili responden dalam menentukan nilai estetika dan daya tarik fasade bangunan.

\section{DAFTAR PUSTAKA}

Birkhoff G. D. (1933). Aesthetic Measure. Cambridge, Harvard University Press.

Ching F. (1996). Architecture; Form, Space, and Order, New York, NY: John Wiley.

Staudek T. (2002). Exact Aesthetics: Object and scene into message. Ph.d. Thesis, Brno, Czechia: Masaryk University, Faculty Of Informatics.

Yordie Wicaksono dan Ary Deddy Putranto (2017). Aspek pembentuk minat beli unit properti. 